\title{
Territórios Sexuais: Análise de Sociabilidades Homossexuais no Shopping Gay de São Paulo
}

\author{
Sexual Territories: analysis of homosexual sociabilities at the gay mall in São \\ Paulo
}

\author{
Bruno Puccinelli \\ Universidade Federal de São Paulo \\ monobruno@hotmail.com
}

\section{Resumo}

Ao apresentar uma etnografia inserida no espaço urbano é importante refletir sobre a ideia de alteridade entre pessoas que participam de perspectivas de vivência e sociabilidade próximas, mas, ao mesmo tempo, não necessariamente iguais; nesse sentido, apresenta-se como um locus privilegiado e que tem se mostrado palco para discursos diversos de pertencimento, fluxos e identidades, o campo desta pesquisa: o Shopping Center Frei Caneca e seus arredores, em São Paulo. O presente artigo pretende apresentar o campo de pesquisa de maneira geral, para se deter mais enfaticamente nos dados colhidos acerca dos fluxos e usos dos frequentadores do shopping, procedendo a uma análise de um processo de generificação identitária de seus territórios: corredores, banheiros e outros espaços.

Palavras-chave: Territorialidade, Gênero, Sexualidade, Consumo, Espaço Urbano.

\begin{abstract}
ntroducing an ethnography inserted in urban space, it is important to reflect on the idea of otherness among people who participate in the perspective of experience and close sociability, but at the same time, not necessarily equal. In this sense, it presents itself as a privileged locus and it has been scenario to various discourses of belonging, flows and identity, the field of this research: Frei Caneca Mall and its surroundings in São Paulo. This article intends to show the researched field in a general way, to focus more strongly in the data collected about the flows and uses of the mall customers, carrying out an analysis of a process of gendered identity in its territories: hallways, restrooms and other spaces.
\end{abstract}

Keywords: Territoriality, Gender, Sexuality, Consumption, Urban Space. 


\section{Introdução}

Inaugurado em 2001, o Shopping \& Convention Center Frei Caneca, localizado na rua de mesmo nome, no bairro de Cerqueira César, região central da cidade de São Paulo, tem sido palco de discursos diversos de pertencimento, fluxos e identidades no que se refere à já bastante divulgada frequência de públicos homossexuais $^{1}$. Desde 2003, pelo menos, pode-se contextualizar uma maior divulgação de tal frequência devido a alguns acontecimentos relativos a descontinuidades da administração do shopping com seu público 'peculiar': neste ano um casal de homens foi convidado a se retirar do shopping por um segurança por estar trocando beijos em público, fazendo com que o local fosse alvo de processo com base em lei anti-discriminatória estadual ${ }^{2}$ e um protesto público na sua praça de alimentação intitulado beijaço $^{3}$. A partir de então o local passou a ser conhecido pela presença de homossexuais masculinos, principalmente, ganhando apelidos que faziam referência a isso, como Frei Boneca e Gay Caneca (CARVALHO, 22/06/2003).

No bojo deste contexto, e de uma situação econômica favorável a um expressivo incremento imobiliário na cidade de São Paulo, bem como o crescimento dos estabelecimentos comerciais de lazer preferencialmente destinados a um público GLS ou gay-friendly, a Rua Frei caneca também ficou conhecida pela prevalência da frequência de homens homossexuais. Dentro deste circuito $^{5}$ homossexual da Frei Caneca, pode-se incluir também fluxos significativos na Rua Augusta, paralela, dotada de públicos diversificados, seja no poder aquisitivo, seja nas classificações por gênero, sexualidade e estilos de vida marcadamente diferentes (VEGA, 2008), no que se convencionou chamar marcadores sociais da diferença. Há de se localizar também alterações cartográficas e deslocamentos recentes de circuitos homossexuais neste período, antes localizada na região do bairro dos Jardins, na Rua da Consolação próximo à Avenida Paulista, com diversos estabelecimentos comerciais e de lazer direcionados aos gays e lésbicas, hoje fechados.

Mais recentemente a Rua Frei Caneca tem ganhado destaque devido à polêmica criada em torno do projeto de oficializá-la como uma rua temática gay, apresentado por uma associação GLS, a qual pretende, além deste projeto (que inclui a 'revitalização' do logradouro), destinar parte de seus trabalhos para a área de saúde e acolhimento de pessoas em situação de rua, todos direcionados à comunidade homossexual. Neste contexto, destaca-se a especial ênfase dada à definição identitária do Shopping Frei Caneca como gay devido à presumida presença majoritária de homossexuais masculinos, os gays ${ }^{6}$ às suas dependências, incluindo aí a identificação de espaços preferenciais de trajetos.

Assim, compreender a dinâmica dos fluxos e deslocamentos de determinado grupo na perspectiva da atribuição de uma identidade sócio-sexual, não apenas personológica, mas também territorial, constitui um dos focos principais do artigo, a fim de contribuir para uma discussão mais ampla que congregue trabalhos focados nas dinâmicas citadinas, por um lado, e da atribuição de identidades sexuais e de gênero, por outro. A noção da constituição de um gueto ajuda a embaralhar essas duas perspectivas, juntar a questão urbana com as definições de pertencimentos e legitimações acionadas pela identidade sexual, e certamente é um dos pontos mais controversos dos discursos, contribuindo para algumas ênfases com relação à rua.

Mas é possível vislumbrar fluxos e contra-fluxos e circuitos em constante movimento que ajudam a constituir espaços de afirmação identitária na região, principalmente no shopping (FRÚGOLI JR., 2008) a partir de dinâmicas de encontro e sociabilidade próprias e não isentas de conflitos.

\section{Novo 'Gueto' Paulistano? Da Rua Frei Caneca à Rua Augusta}

Antes de me ater especificamente ao contexto observado nas dependências do Shopping Frei Caneca, irei apresentar alguns dados relativos à rua que se tornaram parte da reflexão sobre territorialidades sexuais. Isso não quer apontar necessariamente a afirmação de espaços de uso exclusivo de determinado grupo, seja identificado de forra ou de dentro do mesmo, mas apenas ajudar a problematizar a questão, inclusive da definição de um grupo homossexual masculino homogêneo.

Uma questão que se mostrou importante de ser explorada, e que até hoje gera discussões, foi a polêmica criada em torno do projeto de tornar a Rua Frei Caneca oficialmente gay. Alguns atores se tornaram centrais nessa discussão pela ampla utilização da noção de um gueto gay local e uma breve passagem sobre os principais acontecimentos acerca do assunto, ainda em voga, e dados etnográficos auxiliarão numa melhor compreensão dos conflitos sobre a definição das legitimações sobre a Rua Frei Caneca.

Em julho de 2008 o presidente da recém criada Associação GLS Casarão Brasil, Douglas Drumond, apresentou à imprensa o projeto de tornar a Frei Caneca uma rua temática oficial, no caso, uma rua gay.

\section{Bruno Puccinelli}


Baseado em dados de pesquisas na internet sobre qual seria a rua mais gay de São Paulo $^{7}$ e num levantamento visual feito por seu assistente, Drumond definiu a Frei Caneca como uma rua tomada por gays. Segundo suas próprias palavras, "é só olhar na rua para ver, nem

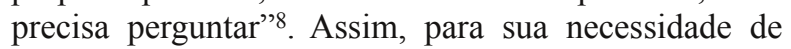
defesa do projeto, bastou um levantamento visual para se definir a prevalência desse público. Segundo a imprensa (PRONSATO, 13/08/2008), o projeto contava ainda com o apoio dos então vereadores Soninha Francine (PPS) e Netinho (PSDB).

Em pouco tempo a Sociedade dos Amigos e Moradores de Cerqueira César (Samorcc), representada pela sua presidente, Célia Marcondes, se posicionou contrária ao projeto: "Espero que a Frei Caneca seja uma rua para todos. As ruas são públicas, são para todos. Não podem ser um gueto". Marcondes ainda argumentou que nem todos os moradores da rua seriam gays e que os mesmos não poderiam conviver com esse estigma; também salientou a existência de crianças e idosos e uma paróquia centenária na Frei Caneca como dados a serem considerados sobre o assunto.

Juntou-se à discussão a Associação da Parada LGBT $^{9}$ de São Paulo (APOLGBT), responsável pela organização da Parada do Orgulho LGBT de São Paulo e uma das principais articuladoras da militância homossexual na cidade. Para a APOLGBT, criar uma rua temática gay seria criar um espaço de segregação para os homossexuais, um 'gueto', quando na verdade se necessitava brigar pela aceitação das 'minorias sexuais' em todos os logradouros da cidade.

Boa parte da literatura que se debruçou sobre os guetos gays de São Paulo tomou como exemplo as pesquisas norte-americanas sobre o caso paradigmático de alguns bairros da cidade de São Francisco (LEVINE, 1979). No caso brasileiro, a expressão não foi transportada sem uma série de mediações: muitas vezes referente a um agrupamento fluido de estabelecimentos comerciais dirigidos a ou frequentados por gays, o gueto era a expressão da circulação de lazer destes indivíduos ou um marcador político importante de afirmação de existência pública e visível ${ }^{10}$. No entanto, a noção do nomadismo característico dos movimentos deste grupo como articulada por Perlongher sobre o gueto gay paulistano, ligando-o à definição de região moral ${ }^{11}$ da Escola de Chicago, fornece um importante ponto inicial de reflexão para as mudanças territoriais recentes nos espaços de sociabilidade gay da cidade, como no bairro dos Jardins.

Mesmo a noção de circuito gay na região da Frei Caneca deve ser relativizada: apesar de existir uma concentração de estabelecimentos identificados com um adesivo não foi possível observar um espaço contíguo ou minimamente localizável de oferecimento comercial dirigido; note-se também que há mudanças constantes nos endereços destes locais. Além disso, a maior parte destes estabelecimentos se encontra na calçada próxima ao shopping e há diversos estabelecimentos apropriados por este público em várias outras partes da cidade e outros tantos na vizinha da Frei Caneca, a Rua Augusta, a qual passa por transformações recentes de incremento comercial e diferenciação de público.

Há até uma discordância local entre qual das duas ruas teria iniciado o processo de alterações e melhorias na região: se a inauguração do shopping, as construções imobiliárias e a presença gay na Frei Caneca, ou a inauguração de bares e casas noturnas e a ocupação da rua cada vez mais por indivíduos de melhor poder aquisitivo em detrimento das prostitutas na Augusta, conforme pôde ser visto em campo. O certo é que a etnografia permitiu observar um espaço de circulação contígua entre os frequentadores de ambas na ligação feita pela Rua Peixoto Gomide, local especialmente marcador de diferenças identitárias.

A Rua Augusta, após a abertura de algumas casas noturnas direcionadas a estilos musicais como o rock e a música eletrônica, observou a tomada de seus espaços por um grupo genericamente chamado de $e^{\text {emos }}{ }^{12}$. Além de ocuparem boa parte de suas calçadas nas noites de sexta-feira, algumas turmas ficam sentadas nas calçadas do quarteirão da Peixoto Gomide que a liga à Frei Caneca, bebendo e conversando, enquanto se observa um fluxo constante de pessoas em direção a esta última. Aparentemente misturados neste espaço, gays e emos, um olhar atento percebe uma gradual mudança de público conforme se caminha para a Frei Caneca: diminui-se a quantidade de emos em decorrência do aumento de gays. Vega (2008) discorre, em recente pesquisa, sobre a dinâmica identitária na Augusta, amplamente permeada por conflitos relativos a clivagens como a performance de gênero, classe e raça, com as atitudes afeminadas vistas negativamente. Relações conflituosas entre os diferentes grupos são comuns e foram atestadas em campo e na imprensa ${ }^{13}$. Nota-se um processo de diferenciação simbólica, pois ambos não impedem frontalmente a permanência num ou noutro espaço. Além disso, pode-se inferir o quanto indivíduos de um ou outro grupo não se reconheceriam em ambos, apesar de um discurso mais geral que empreende separações identitárias fixadas. 


\section{'Azarando no Shopping': Fluxos Desejantes e Espaços de Consumo}

Inicialmente a pesquisa se deteve mais atentamente no próprio Shopping Frei Caneca ${ }^{14}$, a fim de compreender os usos e dinâmicas internas entre os diversos tipos de frequentadores, lojistas e outros atores sociais, ante a ideia geral da presença majoritária de gays, e esse local foi onde se empreenderam as primeiras inserções em campo; num segundo momento se tornou central dar especial atenção ao movimento da Rua Frei Caneca e adjacências devido a alguns acontecimentos recentes, como será discutido mais à frente.

Quando se pensa em pesquisas sobre shopping centers, dificilmente se encontram trabalhos mais detidos na constituição de sociabilidades entre seus frequentadores ligados por laços simbólicos na perspectiva do consumo. Existem poucas pesquisas nesse sentido, salvo o trabalho pioneiro de Frúgoli Jr. (1990). Não pretendo aqui me debruçar sobre a teoria econômica e social que trata das relações de produção e reprodução inseridas no contexto capitalista, mas pontuar questões surgidas a partir da pesquisa de campo dentro do Shopping Frei Caneca, e também em locais fora dele, nas quais as relações sociais poderiam ser localizadas na chave do consumo de bens tidos como fúteis, não de primeira necessidade, como as definições de identidades sociais. Há de se salientar, nesse sentido, a importância da crítica de Douglas \& Isherwood (2004) sobre as relações de consumo no contexto ocidental, vistas geralmente pela via da satisfação de necessidades básicas de sobrevivência ou da prática hedonista e superficial de aquisição de bens; os dois autores indicam tal ideologia, ligada comumente ao 'indivíduo racional' e às teorias economicistas, e que não consideram a possibilidade da construção simbólica através da valoração de bens. Douglas \& Isherwood tentam, assim, demonstrar que o mundo dos bens é dotado de dados culturais e que, portanto, "dizer de um objeto que ele está apto para o consumo é o mesmo que dizer que o objeto está apto a circular como marcador de conjuntos particulares de papéis sociais" (p. 41); de forma semelhante, é possível dizer que um local como um shopping center está apto a aglutinar determinados "conjuntos de papéis sociais" nem sempre previstos, como demonstram os usos de seus espaços por grupos jovens diversos na pesquisa de Frúgoli Jr. (1990).

Como marcadores de papéis sociais, os 'templos do consumo' marcam identidades e espaços de posicionamento político - como ocorreu em 2003 no Shopping Frei Caneca com o beijaço -, bem como usos não previstos de seus espaços ${ }^{15}$. E mesmo a localização de determinadas identidades sociais pode ser observada em espaços delimitados do shopping, ainda que isso não esteja totalmente deslocado da dinâmica cotidiana local. Aliás, tais identidades sóciosexuais em fluxo muitas vezes se confundem com outras frequências locais e devem ser entendidas relacionalmente.

Um meio encontrado para definir alguns grupos e tentar uma tipificação mais precisa, apesar de não pretender ser definitiva, foi observar alguns códigos corporais e de vestimenta. Vestir roupas da marca X ou Y ajudava não só a me localizar, mas servia para situar grupos comuns ou não. Por exemplo: ostentar músculos numa camiseta justa cria um espaço de interdição de acesso a homens que não estejam se utilizando de códigos parecidos. Outro meio foi observar a intensidade de fluxos em alguns locais do shopping, a existência de espaços para encontros e a interação entre os sujeitos; dessa forma, me portar como frequentador comum do shopping, sentando em bancos e na praça de alimentação, indo aos cafés e às lojas, me permitiu uma visão mais global da dinâmica local. Mas não resolvia meus problemas de inserção ou interação.

Alguns achados merecem destaque, como a descoberta que determinadas lojas de vestuário estavam identificadas mais proximamente a este grupo, observar as interações e conversas entre grupos de amigos e a confluência de casais de homens de mãos dadas e até beijos ocorridos no interior do shopping, algo difícil de se observar na rua. Esses dados são cruciais na constituição de uma identidade média homossexual entre os frequentadores do shopping, num processo etnográfico inicial: conhecer peças específicas de dadas marcas de roupas auxiliou na construção prévia de alguns grupos em afluência para o shopping e em seus corredores.

Dessa forma, pode-se delimitar uma presença bastante intensa de rapazes jovens comumente identificados como gays (por si mesmos e pelos outros) a três lojas de vestuário, especialmente. Uma delas possui ampla divulgação em revistas e sites direcionados ao público gay, publicando, inclusive, um calendário com fotos de homens de cuecas, um dos principais artigos procurados e dispostos em destaque nas vitrines; a outra, existente apenas nesse shopping, também comercializa vestuário masculino, mas chegou a ter uma área de roupas femininas; uma última loja tem também uma frequência considerável de gays, mas em menor número ante as anteriores, além de possuir um espaço físico menor. As duas primeiras lojas citadas ficam uma em frente à outra e formam um espaço de circulação bastante intenso.

Tais lojas servem também como ponto de encontro

\section{Bruno Puccinelli}


e de referência para aqueles que querem informações sobre as festas das casas noturnas GLS. Nessas lojas é comum uma especial ênfase ao consumo de peças íntimas, cuja posse é valorizada dentro do grupo mais jovem e que costuma trabalhar o corpo nas academias. Duas dessas lojas estão apenas no Shopping Frei Caneca e uma também na Rua Franca, próximo ao local dos Jardins que antes possuía uma grande concentração de estabelecimentos voltados aos gays (FRANÇA, 2006, p. 49-51).

Há um aspecto simultaneamente público e privado dos shopping centers, permitindo um acesso de determinadas pessoas e ao mesmo tempo limitando-o a outras, aliado à expectativa de que a maior parte dos frequentadores estivessem em momentos de lazer no uso do shopping, como ficou claro em muitas das falas coletadas, foram empecilhos razoáveis na aproximação com informantes e se tornou um dado etnográfico significativo, visto que espera-se estar neste espaço "fechado" sem se ser importunado por outrem. Essa perspectiva informa também um dos usos do shopping feito por vários frequentadores homossexuais, qual seja o de andarem livremente com seus companheiros, travarem contatos de paquera e conhecimento mútuo e, como tratarei mais à frente, contatos sexuais furtivos em espaços específicos, por se encontrarem livres de infortúnios, garantido pela segurança do local, um dos agentes que garante a existência deste espaço aberto, mas proibido a certos grupos indesejáveis, como moradores de rua; tal dinâmica, no entanto, não está isenta de ambiguidades.

É relevante salientar que há, ao mesmo tempo, uma aceitação e uma recusa do espaço do shopping e da Rua Frei Caneca como especialmente frequentados por gays no contexto dos discursos e das relações cotidianas observadas. Muitos dos informantes que se reconheciam como homossexuais afirmavam haver uma frequência grande deste grupo, localizando-a por certos aspectos como um tipo de roupa específica, um determinado corte de cabelo, trejeitos e entonação de voz. Muitos deles também não se incluíam nos grupos que classificavam, afirmando fazerem uso restrito e esporádico do shopping. Um caminho para a compreensão desta atribuição identitária que perpassa uma série de categorias classificatórias talvez possa ser empreendido a partir da análise que Perlongher (2008) faz dos usos dos espaços da cidade ocupados pelos michês, homens que se prostituem: tais espaços possuiriam uma identidade bastante fluida, que auxilia a classificar aqueles que lá se encontram, como uma espécie de identificador mínimo ao que o autor chama de código-território a fim de estipular um espaço minimamente localizável, mas pouco delimitado.

Duas falas exemplificam bem essa questão: quando conversei com um rapaz, migrante do Rio de Janeiro residente nos arredores do shopping há alguns anos, sobre o que ele achava do shopping, o mesmo afirmou ser um lugar 'cheio de mariconas ${ }^{16}$ loucas', se referindo a alguns homens mais velhos que este identificava como gays que circulavam por lá; outro entrevistado afirmou ser 'um lugar com clima de pegação, cheio de gays de meia-idade com grana'. Ambos afirmaram utilizar o shopping apenas para ir ao cinema e comer na praça de alimentação.

Outra fala exemplar sobre a importância do shopping é de um rapaz residente no bairro de Itaquera, Zona Leste da cidade, afirmando ser 'óbvio' o motivo para se deslocar de seu bairro até o Shopping Frei Caneca para ir ao cinema, mesmo havendo boa oferta deste tipo de serviço em sua região. Na ocasião da entrevista, o mesmo estava apresentando o local a um colega da Baixada Santista, litoral sul do estado de São Paulo, que já ouvira falar do shopping. A presença de pessoas de outras cidades e estados é comum, por já terem algum conhecimento de uma presença constante de homossexuais: um outro rapaz do Rio de Janeiro afirmou estar de passagem pela cidade e aproveitou para conhecer o 'shopping gay' de São Paulo, mas disse estar decepcionado porque achou a frequência bem menos intensa do que o imaginado.

Por fim, a observação contínua do espaço permitiu inferir, por exemplo, a pouca presença de casais de mulheres, andando de mãos dadas, ao contrário dos casais masculinos. Dentre estes a maior frequência pode ser observada principalmente aos domingos, sendo que num deles cerca de quinze casais, de mãos dadas ou trocando beijos, circulavam tranquilamente nos corredores. Esse é um dado importante a ser considerado, tendo em vista destacar opiniões positivadas ou negativadas em relação a esses fluxos gays.

\section{Problematizando Questões: Fluxos aos Banheiros}

Além dos passeios e outras atividades de lazer, seguidos de paqueras e trajetos pelos corredores do shopping que propiciavam o contato de olhares, há um uso específico e bastante difundido nos chamados meios gays: a pegação em banheiros públicos ou banheirão $o^{17}$. Tal dinâmica não está isenta de conflitos: há uma placa, visível logo na entrada dos sanitários masculinos, alertando para as penas da prática de ato obsceno em local público ${ }^{18}$ e uma dinâmica de entrada e saída de seguranças e faxineiros para reprimir tais atos. Certa vez, um faxineiro exaltado bradava contra as 'porcarias' que os 'viados' faziam nos banheiros, afirmando ser capaz de agredir fisicamente quem lá

\section{Bruno Puccinelli}


fosse pego. No entanto, tal prática não deixa de existir e é prefigurada por uma série de signos próprios: troca de olhares, gestos e sinais compartilhados em meio ao silêncio.

Mais do que indicar um dado comum à cultura do gueto gay (POLLAK, 1983), a existência do banheirão tem especial significado para se entender algumas classificações identitárias de pertencimento ou exclusão: apesar de negativado nos discursos, muitos dos informantes se dirigiam aos sanitários para tais interações. Um termo nativo de definição dos frequentadores dos banheiros à procura de sexo foi justamente um marcador de idade e performance de gênero: maricona louca. Já se atentou, em outros trabalhos, para a definição particularmente depreciativa de tipos homossexuais masculinos tidos como muito afeminados, por vezes definidos como bichas quá-quá ou poc-poc, nem sempre localizadas como gays, mas como viados, bichas, mariconas ${ }^{19}$. Como citado anteriormente, termos desse tipo eram destinados a outrem, e nunca significavam um encaixe de si nessas classificações. A observação nos espaços permitiu problematizar esse tipo de ordenação no shopping, já que alguns desses frequentadores que se alocavam numa classificação positivada eram também usuários das práticas sexuais nos banheiros do shopping. Mais do que indicar que os mesmo 'mentiam', questão sem sentido a um procedimento qualitativo de pesquisa, esse dado indica o quanto as práticas sociais são permeadas por fluxos e símbolos que estão além da superfície coletada em seus discursos. $\mathrm{Na}$ perspectiva da teoria proposta por Perlongher (2008), tais espaços dos banheiros podem ser entendidos como territorialidades do desejo, espaços de deriva e devir do impulso desejante em fuga.

\section{Fronteiras Movediças: Considerações Finais}

As dinâmicas inter grupais identificadas em campo e citadas aqui, sejam as marcadamente ligadas a um pertencimento identitário homossexual majoritariamente masculino presente na definição dos gays que circulam no shopping e na Rua Frei Caneca, ou nas relações de afastamento para com os emos; ou mesmo os conflitos gerados em torno da definição do espaço da rua como um gueto gay perfazem um trajeto simbólico e territorial fronteiriço de pertencimento pouco preciso. Se o cotidiano dos sujeitos envolvidos neste contexto não denota descontinuidades, uma análise mais detida informa questões problemáticas no que concerne aos territórios identitários mais fixos.

Retomemos o exemplo do banheirão: recortadas por questões de gênero e idade, a prática das trocas sexuais nos sanitários impede seus participantes de integrarem redes sociais mais valorizadas entre aqueles gays frequentadores do shopping, como os círculos formados pelos homens mais jovens frequentadores das lojas destacadas anteriormente. No entanto, é comum que as declarações difamatórias a tal prática venham de pessoas que a façam. Porém, sem demarcar territórios exclusivos, o espaço do shopping delimita transições espaciais: ora pode-se localizar mais para um grupo, o dos 'senhores mais velhos' nos cafés, por exemplo, ora no das mariconas loucas dos sanitários, dependendo do espaço que se ocupa.

Perlongher (2008), ao falar de certo nomadismo territorial no gueto gay, indica um caminho interpretativo interessante para a dinâmica homossexual local, ainda mais se pensarmos nas intersecções identitárias relativas às interações entre gays e entre estes e os emos, por exemplo. A questão da maior ou menor afeminação, dependendo do lugar em que se está - no banheiro ou na Frei Caneca indica um processo de delimitação de fronteiras movediças que devem ser entendidas relacionalmente.

Por fim, apesar de shopping e rua Frei Caneca apresentarem características que os aproximariam de um contexto de enclave ou circuito homossexual, não me sinto à vontade para qualquer determinação neste sentido; tentei, da forma como se apresentou o campo, apresentar alguns pontos importantes de um espaço recheado de limites pouco passíveis de uma delimitação mais precisa. Mais correto seria indicar um espaço propício para a confluência e discursos e fluxos polissêmicos, com a necessidade de maior aprofundamento de algumas questões.

1 Utilizo o termo no plural por entender a maleabilidade das chamadas identidades sexuais, ainda que prevaleça uma ênfase sobre o que genericamente se entende por homossexual masculino, o gay; uma discussão mais profunda sobre o assunto pode ser vista em Fry (1982), Carrara \& Simões (2007) e Butler (2003).

2 ESTADO DE SÃO PAULO. Lei n. 10.948 de 05 de novembro de 2001: 'Dispõe sobre as penalidades aplicadas à prática de discriminação em razão de orientação sexual e dá outras providências'.

3 Protesto comumente utilizado contra a discriminação a homossexuais no qual diversos casais do mesmo sexo se beijam em local público; ver comentários a respeito em FRÚGOLI JR. (2008).

$4 \quad$ GLS é a sigla para Gays, Lésbicas e Simpatizantes e comumente se refere a

\section{Bruno Puccinelli}


estabelecimentos comerciais voltados a este público, enquanto gay-friendly é um expressão amplamente usada nos Estados Unidos para designar estabelecimentos que não discriminam homossexuais (ver França, 2006).

5 Segundo Magnani (1996, 45) a noção de circuito "une estabelecimentos, espaços, e equipamentos caracterizados pelo exercício de determinada prática ou oferta de determinado serviço, porém não contíguos na paisagem urbana, sendo reconhecidos em sua totalidade apenas pelos usuários (...)".

6 A fim de simplificar a leitura, utilizarei apenas o termo genericamente empregado para se referir a homossexuais masculinos, gay, visto que boa parte da atribuição e discussão de pertencimento identitário referente ao lócus da pesquisa está a ele relacionado; além disso, dados etnográficos atestam uma maior presença de homens, ainda que a atribuição de identidades sócio-sexuais estejam subordinadas a outras questões, como performance de gênero, espaços de circulação, etc.

7 Ver a matéria 'Gay Caneca', 21/07/2008 disponível no site MixBrasil.

$8 \quad$ Entrevista realizada em abril/2009.

9 LGBT é a sigla utilizada pelo movimento de defesa dos direitos homossexuais e aglutina as lésbicas, os gays, os bissexuais e os transgêneros (travestis e transexuais).

$10 \quad$ Sobre as diferentes abordagens da expressão ver MACRAE, 1983; FRANÇA \& SIMÕES, 2005; FRANÇA, 2006; PERLONGHER, 2008. Pode-se até inferir sobre a similitude das noções de gueto gay e circuito, como entendido por Magnani, no caso da prevalência de estabelecimentos comerciais direcionados numa dada localidade.

11 "'É inevitável - raciocina Park - que indivíduos que buscam as mesmas formas de diversão devam de tempo em tempo se encontrar nos mesmos lugares.' A população dessas áreas - que nem necessariamente reside, mas apenas perambula pelo local - 'tende a se segregar não apenas de acordo com seus interesses, mas de acordo com seus gostos e temperamentos"' (PERLONGHER apud PARK, 1973, p.64).

$12 \quad$ Segundo Vega (2008, 71): "Emo é um estilo juvenil derivado do punk. Devido ao grande sucesso comercial entre jovens (...) o estilo acabou por se espalhar por várias capitais do país. Devido a disputas simbólicas com outras vertentes do punk, os emos foram bastante criticados e o termo passou a ter um caráter pejorativo fora do círculo dos adeptos do estilo." Apesar de apontar diferenças entre gays e emos, não pretende-se aqui afirmar que os sujeitos do campo não possam se entender num e noutro grupo, apenas a não identificação de falas que levassem a esse entendimento.

13 Ver Redação, 15/06/2009; na noite do dia $12 / 06 / 2009$, às vésperas da realização da $13^{\mathrm{a}}$ Parada do Orgulho LGBT de São Paulo, pude presenciar um rapaz sentado na Rua Peixoto Gomide, próximo à Frei Caneca, ser agedido na cabeça com um skate; seus colegas e outras pessoas no local disseram ser os agressores skinheads, ou punks, ou skatistas, acionando várias das identidades grupais presentes naquele mesmo espaço.

14 O Shopping \& Convention Center Frei Caneca é relativamente alto em relação a outros empreendimentos do tipo, pois boa parte de seus andares concentra espaços disponíveis para a realização de eventos no centro de convenções. Os outros pisos se dividem em: piso inferior, com lojas voltadas a serviços de conveniência como correios, lotéricas e um supermercado; o piso térreo, com lojas de vestuário, perfumaria, eletrônicos; o primeiro piso, com mais lojas de vestuário, merecendo destaque três delas muito frequentadas por gays; o segundo piso, com uma praça de alimentação fast food; e, finalmente, o terceiro piso, com restaurantes a la carte, uma escola de teatro e um complexo de salas de cinema.

15 Sabe-se de happy hours GLS que ocorrem às segundas-feiras no Shopping Metrô Tatuapé, localizado na Zona Leste de São Paulo e frequentado por grupos mais populares (FRÚGOLI JR., 2008, 237238); também na cidade de Suzano, na região metropolitana de São Paulo, há encontros gays aos sábados na praça da prefeitura para confraternização e discussão.

16 Maricona é um termo pejorativo que engloba tanto uma performance de gênero afeminada quanto homens de idades superiores aos quarenta anos.

17 A prática do banheirão, resumidamente, consiste na troca sexual furtiva entre dois ou mais parceiros no espaço do mictório; tais trocas sexuais costumam ser rápidas e silenciosas e não ultrapassam os limites dos toques e da felação. Não demorou muito para que a movimentação nos sanitários fosse percebida em campo.

$18 \quad$ Lê-se na placa: “'A prática de ato obsceno em lugar público, ou aberto ou exposto ao público, é passível de pena de detenção de três meses a um ano' (Artigo 233 do Código Penal) - Respeitar as leis de seu país é garantir seu direito à Cidadania" 19 Ver FRY (1982), CARRARA \& SIMÕES (2007), PERLONGHER (2008), VEGA (2008). 


\section{Referências}

BRAZ, Camilo. Albuquerque . Vestido de Antropólogo: nudez e corpo em clubes de sexo para homens. Bagoas, no 3, p.75-95, 2009.

BUTLER, Judith. Problemas de Gênero. Rio de Janeiro: Civilização Brasileira, 2003.

CARRARA, Sergio; SIMÕES, Júlio. Sexualidade, cultura e política: a trajetória da identidade homossexual masculina na antropologia brasileira. Cadernos Pagu, no 28, p.65 - 99, jan./jun. 2007.

DOUGLAS, Mary; ISHERWOOD, Baron. O mundo dos bens: para uma antropologia do consumo. Rio de Janeiro: Ed. UFRJ, 2004.

FRANÇA, Isadora. Lins. Cercas e pontes. O movimento GLBT e o mercado GLS na cidade de São Paulo. Dissertação de mestrado, Antropologia Social, USP, 2006.

FRÚGOLI JR., Heitor. Os shopping centers de São Paulo e as formas de sociabilidade no contexto urbano. Dissertação de mestrado, FFLCH, USP, 1990.

FRÚGOLI JR., Heitor. Sociabilidade e consumo nos shopping centers de São Paulo: eventos e desafios recentes. In: BUENO, Maria Lucia; Camargo, Luiz Lima. (orgs.). Cultura e consumo: estilos de vida na contemporaneidade. São Paulo: Ed. Senac SP, 2008, p. 231-246.

FRY, Peter. Da hierarquia à igualdade: a construção histórica da homossexualidade no Brasil. In: FRY, Peter. Para inglês ver. Rio de Janeiro: Zahar, 1982.

LEVINE, Martin. Gay ghetto. In: LEVINE, Martin. (org.) Gay men: the sociology of male homossexuality.New York: Harper \& Row, 1979.

MACRAE, Edward. Em defesa do gueto [1983]. In: GREEN, James. N; TRINDADE, Ronaldo. (orgs.) Homossexualismo em São Paulo e outros escritos. São Paulo: Ed. Unesp, 2005, p. 29-308.

MAGNANI, José.Guilherme Cantor. Quando o campo é a cidade: fazendo antropologia na metrópole. In: MAGNANI, José Guilherme Cantor; TORRES, Lillian. de Lucca. (orgs.). Na metrópole: textos de antropologia urbana. São Paulo: Edusp/Fapesp, 1996. p.12-53.
PERLONGHER, Nestor. O negócio do michê [1987]. $2^{\mathrm{a}}$ ed. São Paulo: Editora Perseu Abramo, 2008.

POLLAK, Michel. A homossexualidade masculina, ou: a felicidade no ghetto?. Sexualidades Ocidentais. Lisboa: Contexto, p. 51-73, 1983.

SIMÕES, Júlio; FRANÇA, Isadora Lins. Do 'gueto' ao mercado. In: GREEN, James. N; TRINDADE, Ronaldo. (orgs.) Homossexualismo em São Paulo e outros escritos. São Paulo: Ed. Unesp, 2005, p. 309336.

VEGA, Alexandre Paulino. Estilo e marcadores sociais da diferença em contexto urbano: uma análise da desconstrução de diferenças entre jovens em São Paulo. Dissertação de mestrado, Antropologia Social, USP, 2008.

\section{Matérias de imprensa}

CARVAlHO, Mario Cesar. "Região da Frei Caneca vira 'point' GLS”. Folha de São Paulo, São Paulo, 22/06/2003, p.C8.

PRONSATO, B. "Rua Frei Caneca: ser ou não ser gay”. RRAURL, 13/08/2008, disponível em http://rraurl.uol.com.br/cena/5574/Rua_Frei_Caneca _ser_ou_nao_ser_gay (acessado em 11/01/2009).

REDAÇÃO. “Gay Caneca”. MixBrasil, 21/07/2008, disponível em http://mixbrasil.uol.com.br/upload/noticia/4_151_679 30.shtml (acessado em 23/01/2009).

REDAÇÃO, "Homem sofre traumatismo craniano ao ser espancado em via perto da Parada Gay de SP". FolhaOnLine, São Paulo, 15/06/2009, disponível em http:/www1.folha.uol.com.br/folha/cotidiano/ult95u5 81109.shtml (acessado em 15/06/2009).

Recebido em 17 de julho de 2010. Aceito em 19 de fevereiro de 2011. 